\title{
ScIDoC
}

\author{
International Journal of Dentistry and Oral Science (IJDOS) \\ ISSN: 2377-8075
}

\section{Choice Of Tricalcium Silicate Cements Among Children For Pulp Capping - A Retrospective Study}

Research Article

Akshayaa L ${ }^{1}$, Vignesh Ravindran ${ }^{2 *}$, Madhulaxmi $\mathrm{M}^{3}$

${ }^{1}$ Saveetha Dental College and Hospitals, Saveetha Institute of Medical and Technical Sciences (SIMATS), Saveetha University, Chennai- 77, India.

${ }^{2}$ Senior Lecturer, Department of Pediatric and Preventive Dentistry, Saveetha Dental College and Hospitals, Saveetha Institute of Medical and Technical Sciences [SIMATS], Saveetha University, Chennai- 77, India.

${ }^{3}$ Professor, Department of Oral and Maxillofacial Surgery, Saveetha Dental College and Hospitals, Saveetha Institute of Medical and Technical Sciences [SIMATS], Saveetha University, Chennai- 77, India.

Abstract

Introduction: The fundamental objective of paediatric dentistry involves the preservation of functional primary teeth through various pulp therapies. The significant treatment options for the vital pulp therapy includes pulp capping in adults, partial or complete pulpotomy in children. MTA (Mineral trioxide Aggregate) was the first Tricalcium silicate cement introduced in dentistry and was considered as the gold standard pulp capping agent. Recently developed Tricalcium silicate cements are biodentine, calcium-enriched cement, endosequence.

Aim: The aim of the study was to evaluate the choice of Tricalcium silicate cement among children for pulp capping.

Materials and Methods: The present study was conducted under university setting by analysing 5,00,000 case sheets. The data was collected from case sheets of children who had pulp capping procedures. The collected data were cross verified by another examiner and the final data was obtained. A total of 172 cases were taken and statistically analysed using SPSS software. Results: From the data obtained, it was observed that the most common choice of Tricalcium silicate cement was found to be MTA $69 \%$, when compared to biodentine only about 30\% used for pulp capping among the children aged between 3-17 years. Gender comparison showed no significant differences ( $\mathrm{p}$-value $=0.9$ ).

Conclusion: Within the limitations of the study, we found that MTA was highly preferred by the dentists as a pulp capping material. From the results it has been observed that about $68 \%$ of the children are mostly treated with the MTA.

Keywords: Tricalcium Silicate Cements; Pulp Capping; MTA; Biodentine; Novel Study; Innovative Technique.

\section{Introduction}

The fundamental objective of paediatric dentistry involves the preservation of functional primary teeth through various pulp therapies. The significant treatment options for the vital pulp therapy includes pulp capping in adults, partial or complete pulpotomy in children [1]. There are three endodontic treatment approaches given for primary teeth which incorporate direct pulp capping, pulpotomy, indirect pulp capping. Direct pulp capping and pulpotomy is indicated if the pulp has been exposed. Then, the indirect pulp capping is indicated for the teeth with deep dentinal caries and reversible pulpitis [2]. The success of the vital pulp therapy relies on the choice of pulp capping agents.
An ideal prerequisite of pulp capping material should have: a) ability to stimulate the formation of reparative dentin; b) to maintain pulp vitality; c) should have effective bactericidal action; d) with adequate pulp sealing quality [3]. Tricalcium silicate cement is a type of white ceramic material, composed mainly of calcium silicate, calcium hydroxide, and hydroxyapatite particles [4]. These materials are found to have wide applications in endodontic treatment. It is widely utilised for pulp capping, pulpotomy, resorption defects, perforation repair, for root apexification and as a root canal sealant [5].

MTA (Mineral trioxide Aggregate) was the first Tricalcium silicate cement introduced in dentistry and was considered as the gold standard pulp capping agent. Recently developed Tricalcium

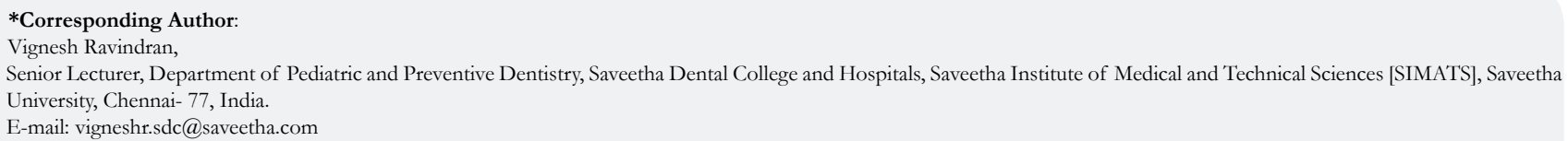

Copyright: Vignesh Ravindran ${ }^{\circ} 2021$. This is an open-access article distributed under the terms of the Creative Commons Attribution License, which permits unrestricted use, distribution and reproduction in any medium, provided the original author and source are credited. 
silicate cements are biodentine, calcium-enriched cement, endosequence etc [6]. The principal benefits of MTA are it is highly biocompatible with good sealing ability. MTA has shortcomings also when utilised for direct pulp capping particularly in children, as it has prolonged setting time, difficult handling properties and causes discolouration of teeth [7]. Another important biomaterial which is known to overcome these limitations is tricalcium silicate cement, a biodentine which was introduced in 2009, to be a second generation hydraulic calcium silicate cement. Biodentine material can be used as a dentin substitute and it is also highly biocompatible. It also reduces the setting time and is significantly involved in the regeneration of pulpal tissues [8].

Several clinical studies have evaluated the preference of Tricalcium silicate cements used for pulp capping procedures. It has been reported that MTA shows $90 \%$ success rate when used as the pulp capping agent in young permanent teeth [9]. A case report study has elicited that biodentine was clinically preferred over other pulp capping materials as it takes a shorter time for setting and is profoundly biocompatible [10]. Our team has extensive knowledge and research experience that has translated into high quality publications [11-23, 24-30]. Thus our present study was aimed to evaluate the choice of Tricalcium silicate cement used for pulp capping among children aged 3-17 years.

\section{Materials and Methods}

A retrospective study was conducted under a university setting. The study was approved by the institutional ethical committee. A total of 5,00,000 case sheets viewing the patient history was collected. Informed consent was obtained from the parents or guardian regarding usage of the clinical data for research purposes.

Inclusion criteria includes children who underwent pulp capping using Tricalcium silicate cement. Patients between 6-17 years of age who had pulp capping were included for the study. And the patients above 18 years who had pulp capping without Tricalcium silicate cement were excluded for the study.
Cross checking of data including digital entry and intraoral photographs was done by an additional reviewer, and as a measure to minimise sampling bias, samples for the group were picked by the simple random sampling method. Digital entry of clinical examination and intraoral photographs were assessed.

The collected data was tabulated in Excel and was then imported to SPSS software (version 23). Descriptive statistics were performed for the obtained results and comparison between groups were done by using Chi square tests.

\section{Results and Discussion}

Out of 5,00,000 case sheets, 172 cases were included four our present study. We evaluated the choice of Tricalcium silicate cement used for pulp capping among the children. Among the children treated with pulp capping, about $53.5 \%$ of them were males and $46.5 \%$ of them were females (Figure 1). About $69.2 \%$ of children were treated with MTA, while $30.8 \%$ of children were treated with biodentine material for pulp capping (Figure 2). MTA was the most commonly used material for both males and females. This shows that there was no difference in usage of the material based on gender of the patient. This was not statistically significant $(\mathrm{p}$ value $=0.908)($ Figure 3$)$.

From the results obtained in our study, it has been observed that MTA is a typical choice of Tricalcium silicate cement used for pulp capping. A previous study with the similar findings has been reported that MTA showed higher success rate and it was considered as the most favourable material for pulpotomy in primary teeth [31]. A previous study done by Noorollahian et al, stated that formocresol is profoundly effective and a preferred pulp capping agent than MTA. As it is more expensive and causes longer duration of clinical procedures [32]. Our study has compared the choice of Tricalcium silicate cement with the gender of the children who had pulp capping. A clinical study similar to this has revealed that MTA showed a preferable clinical impact than other Tricalcium silicate cements for pulp capping done on primary teeth [33]. A previous observational study also revealed that

Figure 1. The bar graph represents the percentage distribution of the gender of children who had pulp capping procedures. It shows that about $53.5 \%$ of them were males and $46.5 \%$ of them were females.

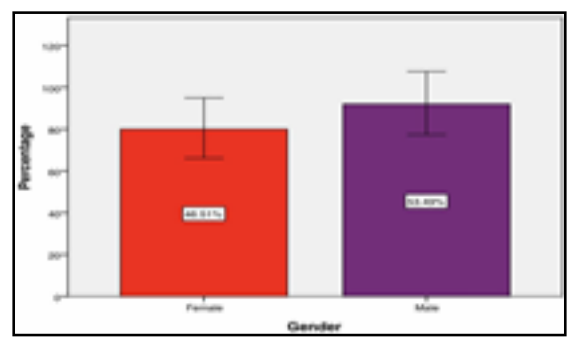

Figure 2. This bar graph represents the percentage of Tricalcium silicate cement preferred for pulp capping among the children. It shows that about $69.2 \%$ of children were treated with MTA, while $30.8 \%$ of children were treated with biodentine material for pulp capping.

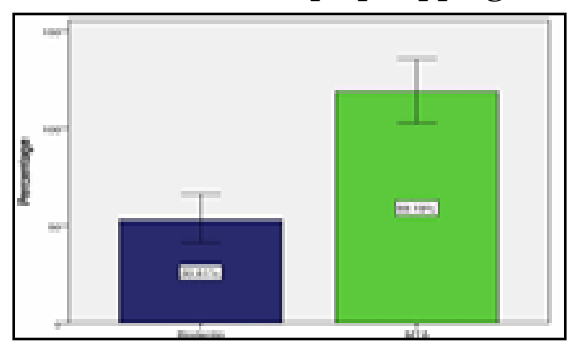


Figure 3. Bar graph represents the association between gender of the children and percentage of Tricalcium silicate cement used for pulp capping procedure. The $\mathrm{X}$ axis represents the gender of the children. $\mathrm{Y}$ axis represents the percentage of two Tricalcium silicate cements used for pulp capping. Here, blue denotes the percentage of children who are treated using biodentine material. Green denotes the percentage of children treated with MTA. MTA was the most commonly used material for both males and females. This shows that there was no difference in usage of the material based on gender of the patient. (Pearson's chi square test value is 0.13 ; $\mathrm{p}$ value $=0.908$ - statistically not significant).

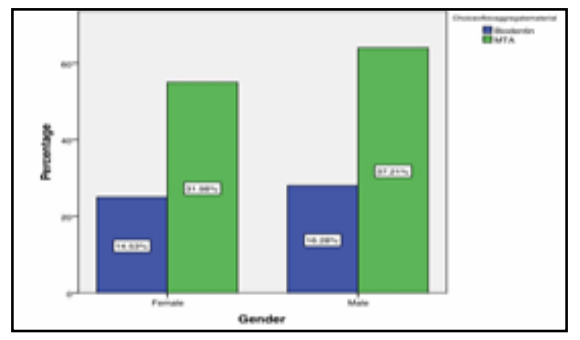

correlation between the gender and choice of Tricalcium silicate cement didn't appear to be statistically significant [34].

In our study we analysed that MTA was highly preferred about $37 \%$ as a pulp capping material, when compared to biodentine, 15\% utilised. Like our findings, another clinical study has assessed that rather than MTA, Calcium hydroxide $\mathrm{CaOH}$ is likewise considered as a better pulp capping agent because of its excellent antibacterial properties [35]. A retrospective clinical study reported that $80 \%$ of clinicians have preferred formocresol over other calcium biosilicate cements as a pulpotomy medicaments for children [36]. Despite the fact that MTA has high clinical success rates, it may not be favoured because of its high cost and difficult handling properties. From our study outcome, we found that MTA was mostly preferred material by the dentist than biodentine for its enhanced pulp sealing effect and biocompatibility. A similar clinical study done among 30 asymptomatic molars in children, have demonstrated that MTA showed a good clinical impact when it is used for the teeth with extreme carious pulp exposures [37]. A previous study done by Schwendicke et al, found that the main reason for which MTA was underused, for its excellent response with high cost benefit when compared to formocresol and $\mathrm{CaOH}$ [38].

Biodentine material seems to be less used pulp capping material among the children as it has recently been introduced. Despite this, it has predominant properties like easier manipulation with good clinical outcomes. But only a few studies were found to be related to the biodentine material [39]. Another study, a 6 month follow-up clinical trial, found that utilization of biodentine is the most reliable choice in vital pulp therapy in primary teeth [40]. Our present study had its own limitations as it is being done in a single university, with a smaller sample size and a shorter time span. Thus the future extent of our study relies on good pulp therapy, the best choice of Tricalcium silicate cement used by the dentist for the pulp capping procedures. However, our study should have a long term follow up for the cases with the goal which will allow us to know the preference of Tricalcium silicate cement being used for pulp capping among the children.

\section{Conclusion}

Within the limitations of the study, we found that MTA was highly preferred by the dentists as a pulp capping material, as biodentine is less used. From the results it has been observed that about $68 \%$ of the children are mostly treated with the MTA. However, with its clinical benefits, mineral trioxide aggregate shows promising material for an indirect pulp capping among the children aged between 3 to 17 years.

\section{Acknowledgement}

The authors are thankful to the Department of Pediatric and Preventive Dentistry,Saveetha Dental College, Saveetha Institute of Medical and Technical science, Saveetha University for providing a platform in expressing their knowledge.

\section{Source of Funding}

The present project was funded by

- Saveetha Dental College,

- Saveetha Institute of Medical and Technical science (SIMATS),

- Saveetha University and

- Lingam stores.

\section{References}

[1]. Bjørndal L, Simon S, Tomson PL, Duncan HF. Management of deep caries and the exposed pulp. Int. Endod. J. 2019 Jul;52(7):949-73.

[2]. Peycheva K. Pulp-Capping with Mineral Trioxide Aggregate. Acta Med. Bulg. 2015;42: 23-9.

[3]. Hamdy M, Fayyad DM, Eldaharawy MH, Hegazy E. Physical properties of different Pulp Capping Materials and Histological Analysis of their effect on Dogs' Dental Pulp Tissue Healing. Egypt. Dent. J. 2018 Jul 1;64:2657-67.

[4]. Zafar K, Jamal S, Ghafoor R. Bio-active cements-Mineral Trioxide Aggregate based calcium silicate materials: a narrative review. J Pak Med Assoc. 2020 Mar;70(3):497-504.Pubmed PMID: 32207434.

[5]. Garrocho-Rangel A, Flores H, Silva-Herzog D, Rosales-Ibańez R, PozosGuillen AJ. Direct pulp capping in primary molars with enamel matrix derivative: report of a case. J Clin Pediatr Dent. 2009 Fall;34(1):9-12.Pubmed PMID: 19953802.

[6]. Drukteinis S, Camilleri J. Bioceramic Materials in Clinical Endodontics. Springer Nature; 2020:101 .

[7]. Vijayran M, Chaudhary S, Manuja N, Kulkarni AU. Mineral trioxide aggregate (MTA) apexification: a novel approach for traumatised young immature permanent teeth. BMJ Case Rep. 2013 Jan 10;2013:bcr2012008094. Pubmed PMID: 23314456.

[8]. Lipski M, Nowicka A, Kot K, Postek-Stefańska L, Wysoczańska-Jankowicz I, Borkowski L, et al. Factors affecting the outcomes of direct pulp capping using Biodentine. Clin. Oral Investig. 2018 Jun;22(5):2021-9.

[9]. Subramaniam P, Konde S, Mathew S, Sugnani S. Mineral trioxide aggregate as pulp capping agent for primary teeth pulpotomy: 2 year follow up study. J. Clin. Pediatr. Dent. 2009 Jul 1;33(4):311-4.

[10]. Butt N, Talwar S, Chaudhry S, Nawal RR, Yadav S, Bali A. Comparison of physical and mechanical properties of mineral trioxide aggregate and Biodentine. Indian J. Dent. Res. 2014 Nov 1;25(6):692. 
[11]. Subramanyam D, Gurunathan D, Gaayathri R, Vishnu Priya V. Comparative evaluation of salivary malondialdehyde levels as a marker of lipid peroxidation in early childhood caries. Eur J Dent. 2018 Jan-Mar;12(1):67-70. Pubmed PMID: 29657527.

[12]. Ramadurai N, Gurunathan D, Samuel AV, Subramanian E, Rodrigues SJ. Effectiveness of $2 \%$ Articaine as an anesthetic agent in children: randomized controlled trial. Clin Oral Investig. 2019 Sep;23(9):3543-50.

[13]. Ramakrishnan M, Dhanalakshmi R, Subramanian EMG. Survival rate of different fixed posterior space maintainers used in Paediatric Dentistry - A systematic review. Saudi Dent J. 2019 Apr;31(2):165-172.Pubmed PMID: 30983825

[14]. Jeevanandan G, Thomas E. Volumetric analysis of hand, reciprocating and rotary instrumentation techniques in primary molars using spiral computed tomography: An in vitro comparative study. Eur J Dent. 2018 JanMar;12(1):21-26.Pubmed PMID: 29657521.

[15]. Princeton B, Santhakumar P, Prathap L. Awareness on Preventive Measures taken by Health Care Professionals Attending COVID-19 Patients among Dental Students. Eur J Dent. 2020 Dec;14(S 01):S105-S109.Pubmed PMID: 33321549.

[16]. Saravanakumar K, Park S, Mariadoss AVA, Sathiyaseelan A, Veeraraghavan VP, Kim S, et al. Chemical composition, antioxidant, and anti-diabetic activities of ethyl acetate fraction of Stachys riederi var. japonica (Miq.) in streptozotocin-induced type 2 diabetic mice. Food Chem Toxicol. 2021 Sep; 155:112374.Pubmed PMID: 34186120.

[17]. Wei W, Li R, Liu Q, Seshadri VD, Veeraraghavan VP, Mohan SK, et al. Amelioration of oxidative stress, inflammation and tumor promotion by Tin oxide-Sodium alginate-Polyethylene glycol-Allyl isothiocyanate nanocomposites on the 1,2-Dimethylhydrazine induced colon carcinogenesis in rats. Arab. J. Chem. 2021 Jun 3;14(8):103238.

[18]. Gothandam K, Ganesan VS, Ayyasamy T, Ramalingam S. Antioxidant potential of theaflavin ameliorates the activities of key enzymes of glucose metabolism in high fat diet and streptozotocin - induced diabetic rats. Redox Rep. 2019 Dec;24(1):41-50.Pubmed PMID: 31142215.

[19]. Su P, Veeraraghavan VP, Krishna Mohan S, Lu W. A ginger derivative, zingerone-a phenolic compound-induces ROS-mediated apoptosis in colon cancer cells (HCT-116). J Biochem Mol Toxicol. 2019 Dec;33(12):e22403. Pubmed PMID: 31714660

[20]. Mathew MG, Samuel SR, Soni AJ, Roopa KB. Evaluation of adhesion of Streptococcus mutans, plaque accumulation on zirconia and stainless steel crowns, and surrounding gingival inflammation in primary molars: randomized controlled trial. Clin Oral Investig. 2020 Sep;24(9):3275-3280.Pubmed PMID: 31955271.

[21]. Sekar D, Johnson J, Biruntha M, Lakhmanan G, Gurunathan D, Ross K. Biological and clinical relevance of microRNAs in mitochondrial diseases/ dysfunctions. DNA Cell Biol. 2020 Aug 1;39(8):1379-84.

[22]. Velusamy R, Sakthinathan G, Vignesh R, Kumarasamy A, Sathishkumar D, Priya $\mathrm{KN}$, et al. Tribological and thermal characterization of electron beam physical vapor deposited single layer thin film for TBC application. Surf. Topogr.: Metrol. Prop. 2021 Jun 24;9(2):025043.

[23]. Aldhuwayhi S, Mallineni SK, Sakhamuri S, Thakare AA, Mallineni S, Sajja R, et al. Covid-19 Knowledge and Perceptions Among Dental Specialists: A Cross-Sectional Online Questionnaire Survey. Risk Manag Healthc Policy. 2021 Jul 7;14:2851-2861.Pubmed PMID: 34262372.

[24]. Sekar D, Nallaswamy D, Lakshmanan G. Decoding the functional role of long noncoding RNAs (lncRNAs) in hypertension progression. Hypertens Res. 2020 Jul;43(7):724-725.Pubmed PMID: 32235913.
[25]. Bai L, Li J, Panagal M, M B, Sekar D. Methylation dependent microRNA $1285-5$ p and sterol carrier proteins 2 in type 2 diabetes mellitus. Artif Cells Nanomed Biotechnol. 2019 Dec;47(1):3417-3422.Pubmed PMID: 31407919.

[26]. Sekar D. Circular RNA: a new biomarker for different types of hypertension. Hypertens. Res. 2019 Nov;42(11):1824-5.

[27]. Sekar D, Mani P, Biruntha M, Sivagurunathan P, Karthigeyan M. Dissecting the functional role of microRNA 21 in osteosarcoma. Cancer Gene Ther. 2019 Jul;26(7-8):179-182.Pubmed PMID: 30905966.

[28]. Duraisamy R, Krishnan CS, Ramasubramanian H, Sampathkumar J, Mariappan S, Navarasampatti Sivaprakasam A. Compatibility of Nonoriginal Abutments With Implants: Evaluation of Microgap at the Implant-Abutment Interface, With Original and Nonoriginal Abutments. Implant Dent. 2019 Jun;28(3):289-295.Pubmed PMID: 31124826.

[29]. Parimelazhagan R, Umapathy D, Sivakamasundari IR, Sethupathy S, Ali D, Kunka Mohanram R, et al. Association between Tumor Prognosis Marker Visfatin and Proinflammatory Cytokines in Hypertensive Patients. Biomed Res Int. 2021 Mar 16;2021:8568926.Pubmed PMID: 33816632.

[30]. Syed MH, Gnanakkan A, Pitchiah S. Exploration of acute toxicity, analgesic, anti-inflammatory, and anti-pyretic activities of the black tunicate, Phallusia nigra (Savigny, 1816) using mice model. Environ Sci Pollut Res Int. 2021 Feb;28(5):5809-5821.Pubmed PMID: 32978735.

[31]. Bodem O, Blumenshine S, Zeh D, Koch MJ. Direct pulp capping with mineral trioxide aggregate in a primary molar: a case report. Int J Paediatr Dent. 2004 Sep;14(5):376-9.Pubmed PMID: 15331004.

[32]. Noorollahian H. Comparison of mineral trioxide aggregate and formocresol as pulp medicaments for pulpotomies in primary molars. Br Dent J. 2008 Jun;204(11):E20.

[33]. Eidelman E, Holan G, Fuks AB. Mineral trioxide aggregate vs. formocresol in pulpotomized primary molars: a preliminary report. Pediatr Dent. 2001 Jan-Feb;23(1):15-8.Pubmed PMID: 11242724.

[34]. Sruthi MA, Subramanian EM, Ravindran V. Dentists' Preference of Pulp Capping Agent for Indirect Pulp Capping in Primary and Permanent Molars-An Observational Study. Indian J. Forensic Med. Toxicol. 2020 Oct $1 ; 14(4): 5601$

[35]. Graham L, Cooper PR, Cassidy N, Nor JE, Sloan AJ, Smith AJ. The effect of calcium hydroxide on solubilisation of bio-active dentine matrix components. Biomaterials. 2006 May 1;27(14):2865-73.

[36]. Mathew MG, Lecturer S, Department of Pediatric and Preventive Dentistry, Saveetha Dental College And Hospitals, Saveetha Institute of Medical And Technical Sciences, Saveetha University, et al. Preference Of Calcium Biosilicate Cements Used By Dental Students For Treatment Of Immature Non -Vital Permanent Teeth - An Institutional Based Retrospective Study. Int. J. Dent. Oral Sci. 2021: 1451-4.

[37]. Farsi N, Alamoudi N, Balto K, Al Mushayt A. Clinical assessment of mineral trioxide aggregate (MTA) as direct pulp capping in young permanent teeth. J. Clin. Pediatr. Dent. 2007 Jan 1;31(2):72-6

[38]. Schwendicke F, Frencken JE, Bjørndal L, Maltz M, Manton DJ, Ricketts $\mathrm{D}$, et al. Managing carious lesions: consensus recommendations on carious tissue removal. Adv. Dent. Res. 2016 May;28(2):58-67.

[39]. Kunert M, Lukomska-Szymanska M. Bio-Inductive Materials in Direct and Indirect Pulp Capping-A Review Article. Materials (Basel). 2020 Mar 7;13(5):1204.Pubmed PMID: 32155997.

[40]. Sheth PP, Lolayekar NV, Hegde AM. Use of BiodentineTM for Vital Pulp Therapy in Children: Three Case Reports. Indian J Public Health. 2020 May;11(05):341. 